УДК621.941

Аймен Албакуш, О.А. Оргіян, Г.В. Баланюк

Одеський національній політехнічний університет

\title{
ТЕХНОЛОГІЧНА ДИНАМІКА ТОНКОГО РОЗТОЧУВАННЯ ОТВОРІВ МАЛОГО ДІАМЕТРА
}

\begin{abstract}
Анотація. У статті вивчені особливості коливань консольних борштанг малого діаметра (8 - 20 мм). Аналітично отримано умова вібросталості при заданих параметрах замкнутої на процес різання пружної системи. Експериментально визначені характеристики згинних і обертальних коливань. Показана можливість гасіння коливань при накладенні додаткових осьових вібрацій для нестійких борштанг. Вивчено спосіб розширення технологодинамічних можливостей нестійких консольних борштанг шляхом попереднього стиснення розточної оправки, ще забезпечує підвищення згинної жорсткості.
\end{abstract}

Ключові слова: консольна боританга, згинна жорсткість, обертові коливання, осьові вібраиії, замкнута динамічна система.

Встановлено, що коливання при фінішному розточуванні є одним з важливих факторів, що обмежують точність обробки. Ці коливання являють собою відносні статичні і динамічні переміщення ріжучого інструменту і оброблюваної деталі, які і визначають формоутворення профілю поверхні. Таким чином, коливання, що збуджуються в пружно-дисипативнійінерційній системі (ПДІС) верстата, перешкоджають досягненню необхідних показників точності оброблених отворів. Шкідливі коливання впливають на точність обробки, відображаються на експлуатаційних характеристиках обладнання, наприклад, на продуктивності, надійності і довговічності.

Слід зазначити, що значне підвищення якості обробки було досягнуто при використанні статичних і динамічних розрахунків, а також на основі експериментальних досліджень вимушених i самозбуджуючихся коливань. Відомо, що в технологічній динаміці використовують поняття замкнутої динамічної системи верстата, що включає наявність зворотних зв'язків між ПДІС і РП (робочими процесами). Поняття замкнутості дозволяє в першу чергу вирішувати завдання стійкості динамічної системи, а також вивчати вплив ступеня стійкості на характеристики динамічної системи. Тому важливо вивчити ступінь впливу динаміки процесу розточування на точність і мінімізувати похибки при металообробці [1].

Відзначимо також, що в технологічній динаміці досліджуються і проблеми корисного використання вібрацій при різанні, особливо при використанні умов ефективного застосування вібраційного різання [2].

Динамічні системи зі змінними параметрами називають нестаціонарними. До нестаціонарності призводить, наприклад, змінність жорсткості, що призводить до віджиму різця, або нерівномірність припуску на оброблюваній деталі і ін.

Навіть простий аналіз технологічних систем показує, що збудження коливань в стаціонарних технічних системах (тобто при постійних параметрах динамічної системи) реалізується для автоколивань в нелінійних системах, а також при впливах на верстат навколишнього обладнання. Всі інші джерела збудження коливань пов'язані з перемінністю параметрів динамічної системи.

Незважаючи на широке використання консольних борштанг, а також велику кількість публікацій що до коливань і особливостей тонкого розточування, слід зазначити, що динамічні взаємодії і вібросталість процесу для борштанг з діаметром менше 15 мм вивчено явно недостатньо, хоча в багатьох деталях (в корпусах гідроапаратури, вилках, шатунах і ін.) є точні отвори малих діаметрів з відношенням $1 / \mathrm{d}>3 \mathrm{x}$, де 1 - довжина отвору, $\mathrm{d}$ - діаметр. Складність обробки таких отворів полягає в конструктивних особливостях борштанг малого діаметра $\left(\mathrm{d}_{6}=8-20 \mathrm{MM}\right)$ :

- установка віброгасників 3 необхідними характеристиками для гасіння коливань обмежена через конструктивні неможливості виконання достатньої порожнини під їх установку;

- мала згинальна жорсткість консольних борштанг (табл. 1).

- спільна дія згинних і обертальних коливань, що впливають на якість розточування;

- недостатня вібросталість консольних борштанг при збільшенні глибини різання.

Динамічна характеристика ПР враховує дві важливих особливості:

- інерційність процесу різання, тобто відставання по фазі сили різання від зміни товщини зрізу; 
- залежність сили різання від швидкості зміни товщини зрізу.

Податливість деяких консольних борштанг

\begin{tabular}{|c|c|c|}
\hline \multicolumn{3}{|c|}{ борштанга } \\
\hline d, мм & 1, мм & К, мкм / H \\
\hline \multirow{3}{*}{15} & 30 & 0,06 \\
& 45 & 0,1 \\
& 60 & 0,21 \\
\hline \multirow{3}{*}{12} & 75 & 0,4 \\
\hline & 24 & 0,05 \\
& 36 & 0,09 \\
\hline
\end{tabular}

Таблиця 1

$$
T_{p} \dot{P}+P=-k_{p} \sin \varphi_{u} u+k_{s} \cos \varphi_{u} \dot{u}
$$

де $\mathrm{T}_{\mathrm{p}}$ - постійна часу стружкоутворення, що характеризує інерційність процесу,

$\varphi_{u}$-кут, який проектує напрямок коливань на напрям головного руху [3]

$\mathrm{k}_{\mathrm{p}}$ - коефіцієнт різання,

$\mathrm{k}_{\mathrm{s}}$ - швидкісний коефіцієнт,

$\dot{P}$ - похідна сили різання по часу.

При збігу напрямків сили різання і головних осей жорсткості системи можна прийняти $\mathrm{k}_{\mathrm{s}}=0, \mathrm{a} \sin \varphi_{u}=1$. вільності:

Запишемо рівняння руху замкнутої динамічної системи верстата 3 одним ступенем

$$
\left\{\begin{array}{l}
m \ddot{y}+b \dot{y}+c y=P \\
T_{p} \dot{P}+P=-k_{p} y
\end{array}\right.
$$

де у - радіальне коливальне переміщення різця щодо деталі,

$\dot{y}, \ddot{y}$ - швидкість і прискорення коливальних переміщень,

$m$ - приведена маса пружної системи,

$b$ - коефіцієнт дисипації,

с - жорсткість пружної системи в напрямку головної складової сили різання, $\mathrm{T}_{\mathrm{p}}=\mathrm{a} / \mathrm{v}$, $\mathrm{a}$ - товщина стружки, $\mathrm{v}$ - швидкість різання.

Для розрахунку критерію стійкості, використовуючи значення першої власної частоти пружної системи $\omega_{0}=\sqrt{\frac{c}{m}}$, введемо безрозмірні параметри - безрозмірний час $\tau=\omega_{0} t$.

Рівняння (1) представимо у вигляді

$$
\left\{\begin{array}{l}
m \omega_{0}^{2} \ddot{y}+b \omega_{0} \dot{y}+c y=P \\
T_{p} \omega_{0} \dot{P}+P=-k_{p} y
\end{array}\right.
$$

Після перетворень і введення позначень для безрозмірних параметрів $\Omega=\frac{b}{m \omega_{0}}$, дисипація, $\Theta=\omega_{0} T_{p}$ система (2) набуде вигляду:

$$
\left\{\begin{array}{l}
\ddot{y}+\Omega \dot{y}+y=\frac{P}{c} \\
\Theta \dot{P}+P=-k_{p} y
\end{array}\right.
$$

Від рівнянь (3) перейдемо до одного диференціального рівняння:

$$
\Theta \dddot{y}+(1+\Theta \Omega) \ddot{y}+(\Theta+\Omega) \dot{y}+(1+\gamma) y=0,
$$


де $\gamma=\frac{k_{p}}{c}$ - коефіцієнт зв'язаності пружної системи з ПР.

Характеристичне рівняння має вигляд:

$$
a_{0} z^{3}+a_{1} z^{2}+a_{2} z+a_{3}=0
$$

де $a_{0}=\Theta ; a_{1}=1+\Theta \Omega ; a_{2}=\Theta+\Omega ; a_{3}=1+\gamma$.

Відповідно до критерію Рауса - Гурвіца стійкість реалізується при:

$$
\begin{gathered}
a_{0} \succ 0 ; a_{1} \succ 0 ; a_{3} \succ 0 \text { і } a_{1} a_{2}-a_{0} a_{3} \succ 0, \text { тобто } \\
(1+\Theta \Omega)(\Theta+\Omega)-\Theta(1+\gamma) \succ 0,
\end{gathered}
$$

звідки

$$
\gamma \prec \Omega\left(\Theta+\Theta^{-1}+\Omega\right) .
$$

позначаючи $\Omega\left(\Theta+\Theta^{-1}+\Omega\right)=\gamma_{0}$ - граничне значення коефіцієнта зв'язаності пружної системи з ПР, отримаємо

$$
\gamma \prec \gamma_{0}=\Omega\left(\Theta+\Theta^{-1}+\Omega\right)
$$

Вираз (6) дозволяє, знаючи параметри замкнутої динамічної системи, прогнозувати стійкість і працездатність інструменту при різанні.

Загальні види та схеми експериментальних стендів, зібраних на базі обробнорозточувального верстата з горизонтальними шпиндельними головками, наведені на рис. 1 i 2. Елементи стендів позначені на схемах.

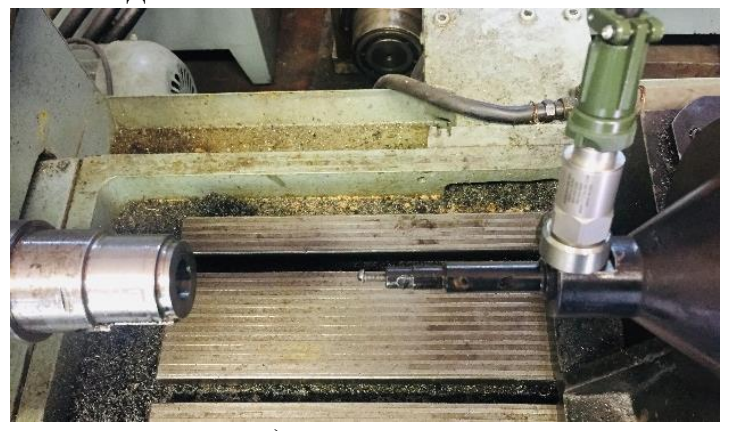

a)

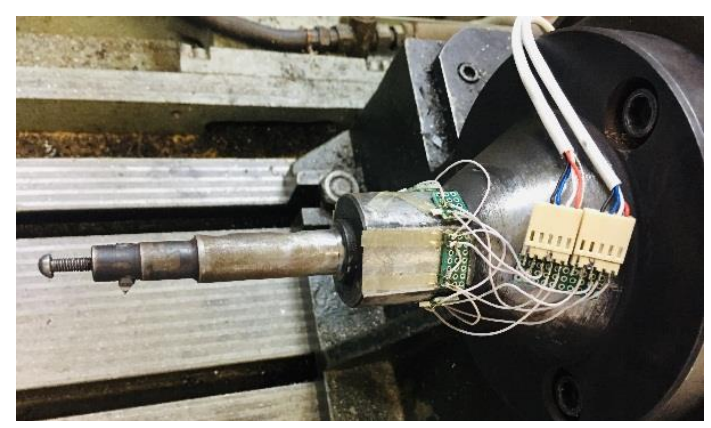

б)

Рис. 1. Експериментальні стенди: а) з п'езодатчиком; б) з тензодатчиками

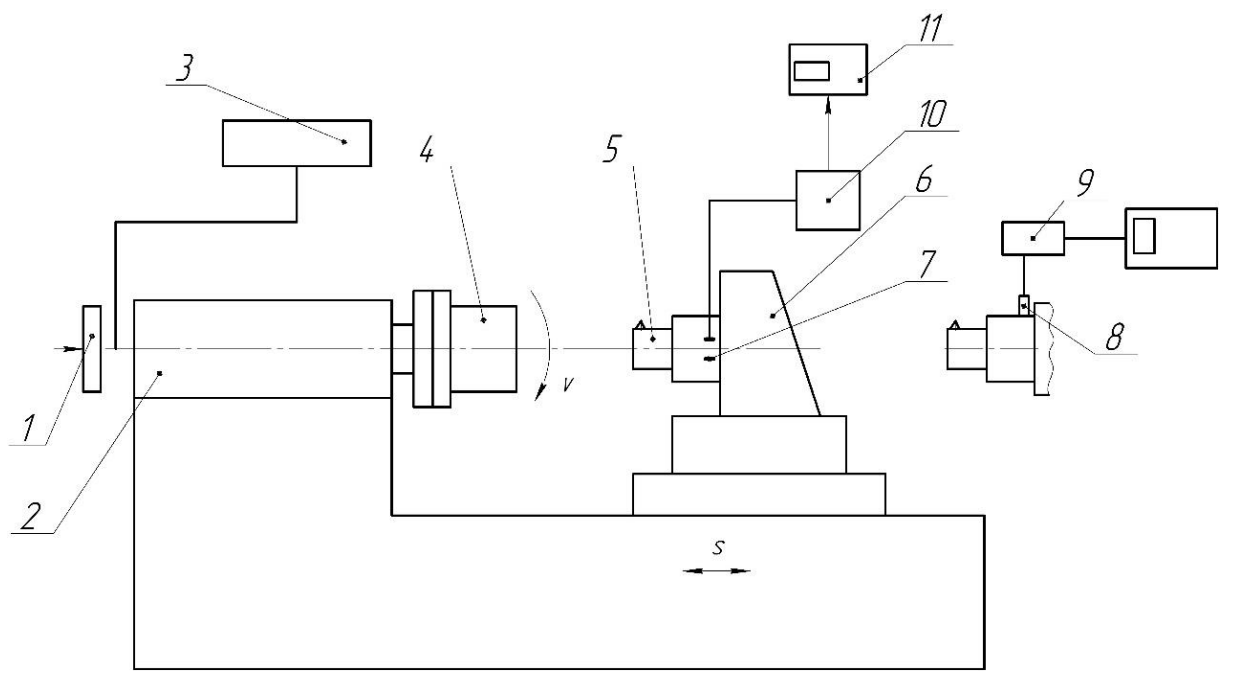

Рис. 2. Схеми експериментальних стендів для дослідження коливань борштанг:

1 - тахометр; 2 - шпиндельна головка; 3 - перетворювач частоти; 4 - заготовка;

5 - борштанга; 6 - пристосування; 7 - тензорезистори; 8 - п'езодатчик; 9 - аналізатор спектру вібрацій; 10 - пристрій реєстрації коливань; 11 - персональний комп'ютер.

Оброблялися зразки зі сталі 45 і чавуну СЧ-18 консольними борштангами діаметрами $\mathrm{d}_{1}=10,12,15$ і 20 мм при $1 / \mathrm{d}>4$, тобто вивчалися нестійкі режими. Частоти обертання 
шпинделя $\mathrm{f}_{\text {шп }}=16,18,20$ і 25 Гц при швидкості різання $\mathrm{v}=150-200 \mathrm{~m} /$ хв, глибинах різання $\mathrm{t}_{\mathrm{p}}=0,05$ i 0,07 мм, i подачах $\mathrm{S}=28$ i 40 мм/хв. Вимірювалися амплітуди коливань різця $\mathrm{a}_{\mathrm{y}}, \mathrm{a}_{\mathrm{z}} \mathrm{i}$ $\mathrm{a}_{\mathrm{o}}$, викликані відповідно вигинами в горизонтальному i тангенціальному напрямках до оброблюваної деталі, і обертальні коливання.

Для амплітуд коливань виконуються співвідношення $\mathrm{a}_{\mathrm{o}}=(0,1-0,6) \mathrm{a}_{\mathrm{y}}, \mathrm{a}_{\mathrm{z}}=(1,1-1,5) \mathrm{a}_{\mathrm{y}}$, причому $\mathrm{a}_{\mathrm{o}} / \mathrm{a}_{\mathrm{y}}$ значно зменшується зі збільшенням діаметра борштанги. Збільшення глибини різання $t_{p}$ призводить до спільного росту всіх амплітуд. Згині коливання розвиваються на частотах 0,4 - 2 кГц на діаметрах більших 12 мм, а на менших діаметрах з'являються високочастотні гармоніки (3 - 7 кГц), відповідні власним частотам обертальних коливань.

На рис. 3 наведені осцилограми згинних і обертальних коливань, а на рис. 4 осцилограма 3 використанням додаткових осьових вібрацій для дослідження можливості зменшення амплітуд згинних коливань накладенням осьових вимушених коливань 3 амплітудою 0,25 мм при частоті збурення 18 Гц.

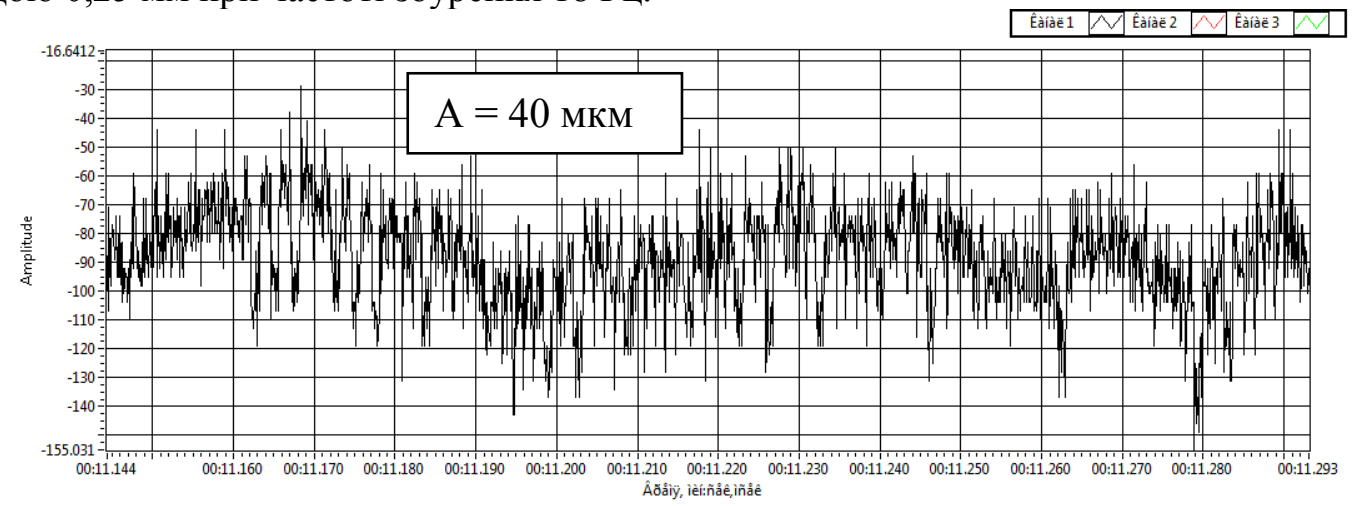

a) згинні коливання - власна частота $\mathrm{f}_{3 г \text {. }}=700$ Гц;

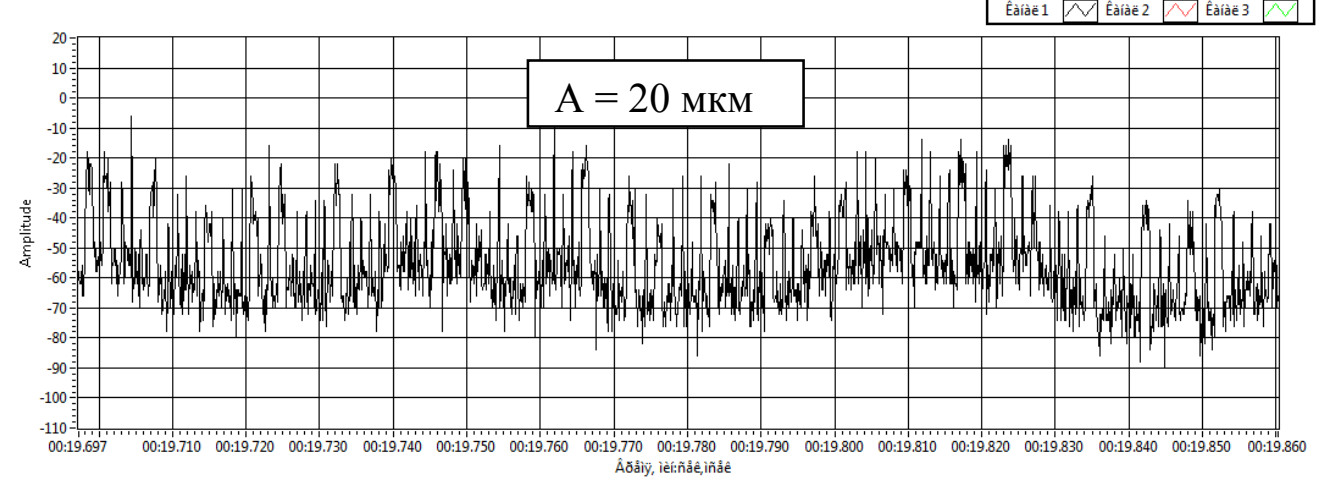

б) обертальні коливання власна частота $\mathrm{f}_{\text {об̆ }}=2000$ Гц

Рис. 3. Осцилограми згинних і обертальних коливань: $\mathrm{n}=980$ об/хв; $\mathrm{S}=0,23$ мм/об; $\mathrm{t}_{\mathrm{p}}=0,05 \mathrm{MM}$.

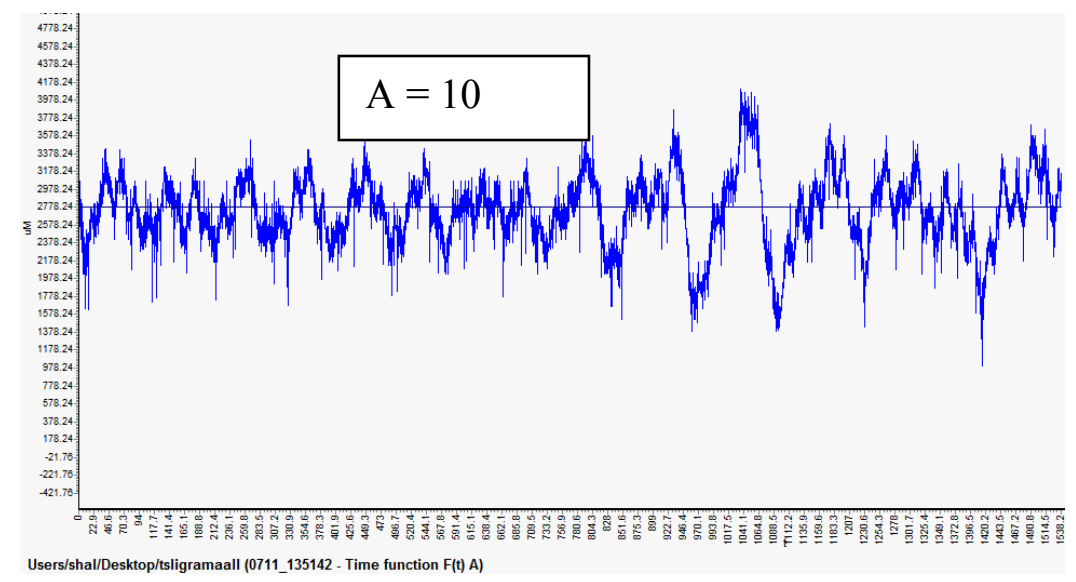

Рис. 4. Осцилограма з використанням додаткових осьових вібрацій $1 / \mathrm{d}=6$ : $\mathrm{n}=980$ об $/ \mathrm{xв} ; \mathrm{S}=0,23$ мм/об; $\mathrm{t}_{\mathrm{p}}=0,05$ мм.

Експерименти свідчать про можливість ефективного гасіння згинних коливань нестійких борштанг з використанням додаткових осьових вібрацій. 
Нами також запропонована конструктивна можливість збільшення згинної жорсткості борштанг малого діаметра шляхом попереднього стиснення таких оправок.

В експериментах, виконаних на трубах, попередньо стиснутих за допомогою вставлених у них шпильок, діаметром приблизно рівним внутрішньому діаметру труби, при різних осьових стискаючих зусиль (рис.5), були отримані значення збільшених жорсткостей.

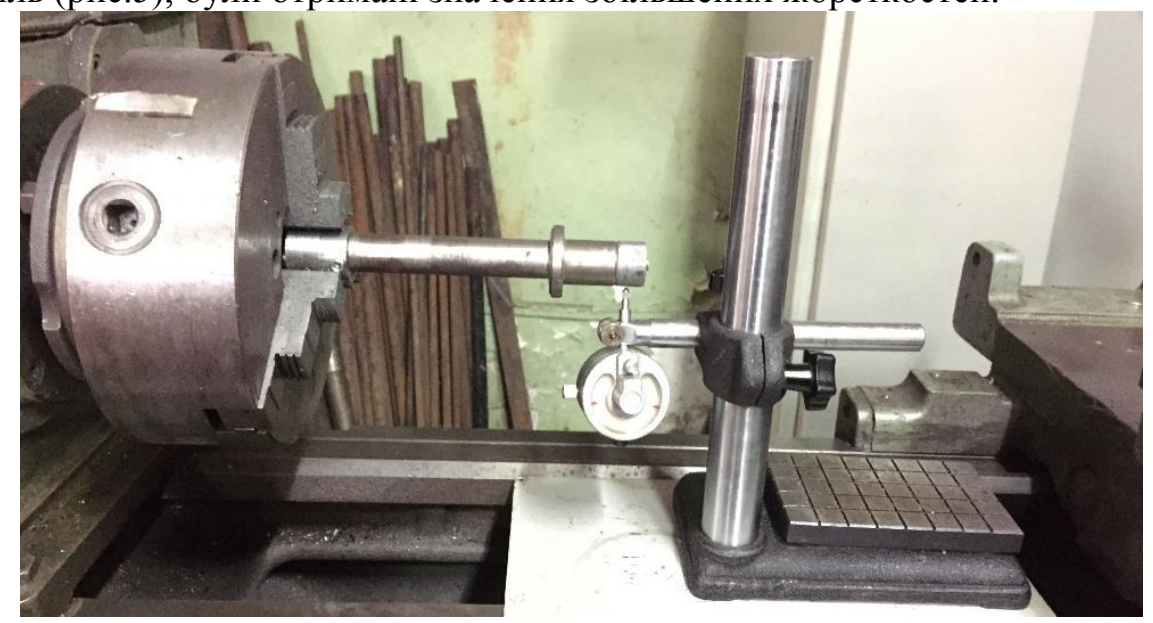

Рис. 5. Вивчення згинної жорсткості попередньо стиснутих труб.

Шпильки загвинчують в труби за допомогою динамометричних ключів, а згинні жорсткості вимірювалися в радіальному напрямку.

На рис. 6 представлена конструкція борштанги 3 попереднім стисненням осьовим зусиллям, а в таблиці 2 наведені значення жорсткостей.

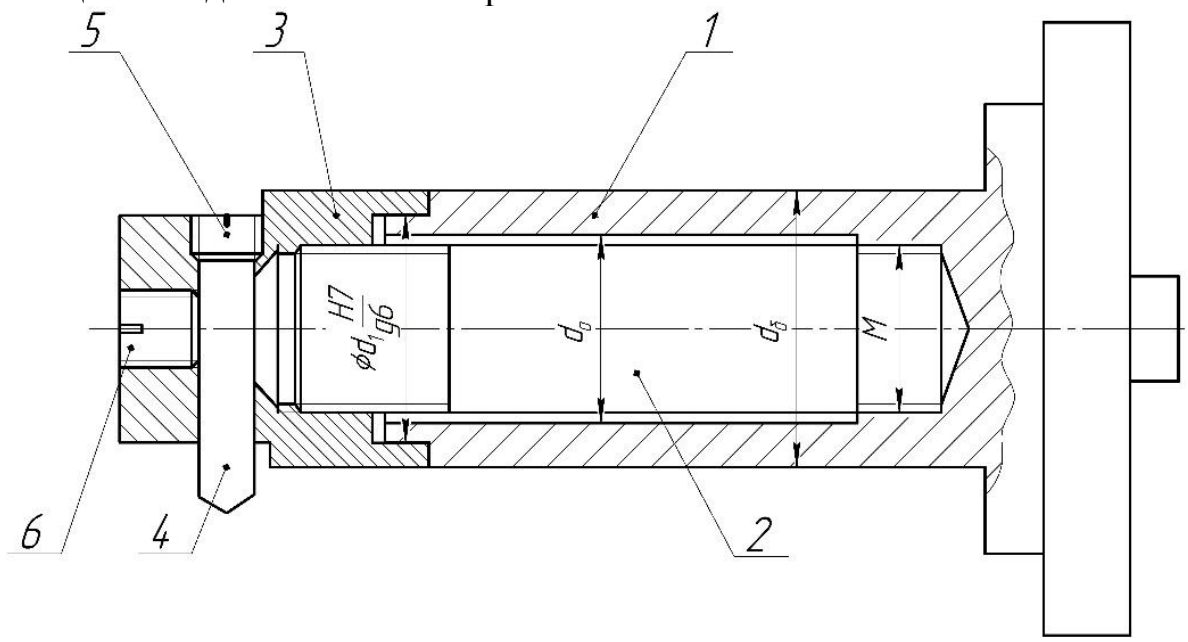

Рис.6. Конструкція борштанги з попереднім стисненням: 1 - корпус; 2 - шпилька; 3 - різцеутримувач; 4 - різець; 5, 6 - регулювальні гвинти.

Таблиця 2

Значення згинних жорсткостей борштанги при зміні значень осьових зусиль

\begin{tabular}{|c|c|c|c|c|}
\hline \multicolumn{4}{|c|}{ Борштанга $\mathrm{d}=16$ мм, $1 / \mathrm{d}=6$} \\
\hline радіальне & без навантаження & \multicolumn{3}{|c|}{ Осьові зусилля стиснення, $\mathrm{H}$} \\
\cline { 3 - 5 } навантаження & & 4000 & 8000 & 13000 \\
\hline $20 \mathrm{H}$ & $2,5 \mathrm{H} /$ мкм & $2,9 \mathrm{H} /$ мкм & $3,2 \mathrm{H} /$ мкм & $3,3 \mathrm{H} /$ мкм \\
\hline
\end{tabular}

Слід також зазначити, що збільшення сили стиснення борштанг призводить до збільшення їх жорсткості, що дозволяє збільшити довжину розточування i забезпечує зменшення амплітуд вимушених коливань в 2-3 рази.

Висновки:

- Консольні борштанги $з$ діаметрами менше 20 мм мають малу вібросталість.

- Аналітично виведено умову вібросталості борштанг при заданих умовах обробки. 
- Вивчено особливості вимушених коливань, наведені характеристики згинних і обертальних форм, а також їх співвідношення амплітуд і частот.

- Показана можливість гасіння згинних коливань 3 накладенням додаткових осьових вібрацій.

- Вивчено розширення технолого-динамічних можливостей консольних борштанг за рахунок попереднього стиснення, що призводить до підвищення згинної жорсткості i вібросталості.

\section{Література}

1. Кудинов В.А. Динамика станков. - Машиностроение, 1967. - 360 с.

2. Подураев В.Н. Обработка резанием с вибрациями. / В.Н. Подураев. М.: Машиностроение, 1970. $-352 \mathrm{c}$.

3. Копелев Ю.Ф., Оргиян А.А., Кобелев В.М. Параметрические колебания металлорежущих станков. / Под общей редакцией Копелева Ю.Ф. - Одесса: Печатный дом, ОНПУ, 2007. - 352 с.

4. Оргиян А.А. Особенности колебаний борштанг для тонкого растачивания. / Оргиян А.А., Баланюк А.В. / "Сучасні технології в машинобудуванні: зб. наук. праць. - Вип. 9 - Харків : НТУ «ХПІ», 2014. - 323 с. -стр. $111-124$.

5. Оргиян А.А. Анализ взаимодействия изгибных и крутильных колебаний при тонком растачивании / А.А. Оргиян, А.В. Баланюк, И.М. Творищук // Матеріали XVI МНTК «Прогресивна техніка, технологія та інженерна освіта», С 231-233, 2015 - 285 м. Одеса, 22 - 25 червня $2015 \mathrm{p}$.

Аймен Албакуш, О.А. Оргиян, Г.В. Баланюк

Одеский национальный политехнический университет

\section{ТЕХНОЛОГИЧЕСКАЯ ДИНАМИКА ТОНКОГО РАСТАЧИВАНИЯ ОТВОРОВ МАЛОГО ДИАМЕТРА}

Анотация. В статье изучены особенности колебаний консольных борштанг малого диаметра (8 - 20 мм). Аналитически получено условие виброустойчивости при заданных параметрах замкнутой на процесс резания упругой системы. Экспериментально определены характеристики изгибных и крутильных колебаний. Показана возможность гашения колебаний при наложении дополнительных осевых вибраций для неустойчивых борштанг. Изучен способ расширения технолого-динамических возможностей неустойчивых консольных борштанг путем предварительного сжатия расточной оправки, что обеспечивает повышение изгибной жесткости.

\section{Aimen Albakoush, A. Orgiyan, A. Balanyuk \\ Odessa National Polytechnic University \\ TECHNOLOGICAL DYNAMICS OF FINE BORING HOLES OF SMALL DIAMETER}

Abstract. The article particularly studied oscillations cantilevered boring bar of small diameter $(8-20 \mathrm{~mm})$. Analytical condition vibrostability obtained with given parameters closed on the process of cutting the elastic system. Experimentally the stands fluctuations console borshtangi studied. In the measurements of forced oscillations used piezoelectric and strain gauges. We define the value of the flexural stiffness and the natural frequencies of the console of the boring bar. In the experiments in accordance with the theory of the vibrating cutting investigated the possibility of unstable damping boring bar $(1 / \mathrm{d}>4)$ using additional axial vibrations with a certain amplitude and frequency. Shows oscillograms of flexural and torsional oscillations, their frequency and amplitude. Submitted estimating the ratio of amplitudes and frequencies of the flexural and torsional oscillations. It provides a method for increasing the flexural rigidity of the boring bar. Investigated increasing the flexural rigidity of the boring bar unstable with $1 / \mathrm{d}>4$ by precompression of the boring bar, which increases vibration during cutting. An example of the construction of prestressed boring bar as well as the values of the flexural rigidity.

Key words: cantilevered boring bar, flexural rigidity, torsional vibration, axial vibration, closed dynamic system. 